\title{
Continuity of supply of psychiatric medicines for newly received prisoners
}

\author{
Lamiece Hassan, ${ }^{1,2}$ Jane Senior, Dawn Edge, ${ }^{3}$ Jenny Shaw ${ }^{1,2}$
}

The Psychiatrist (2011), 35, 244-248, doi: 10.1192/pb.bp.110.031757

'Offender Health Research Network, University of Manchester; ${ }^{2}$ Lancashire Care NHS Foundation Trust, Preston; ${ }^{3}$ School of Community Based Medicine, University of Manchester Correspondence to Lamiece Hassan (lamiece.hassan@nhs.net)

First received 1 Jul 2010, final revision 15 Oct 2010, accepted 16 Dec 2010

\begin{abstract}
Aims and method A retrospective case-note review was undertaken at five English prisons between June 2008 and March 2009 to estimate the proportion of psychiatric medicines (antidepressants, antipsychotics and hypnotics/anxiolytics) reported at prison reception that are discontinued on entry to prison.
\end{abstract}

Results Of the 1006 records sampled, the review showed that $18 \%$ of prisoners had been prescribed psychiatric medication before being placed in custody. Altogether, 240 separate psychiatric medicines were recorded among prisoners at reception. Of these, $47 \%$ were not prescribed during the first week of custody. In only $11 \%$ of cases where medication was discontinued had psychiatric assessment been completed.

Clinical implications Prison mental health policy states that psychiatric medication should not be withdrawn in custody without proper clinical assessment. Denial of medication in the absence of clinical assessment during early custody has the potential to create additional stress in individuals during a period of increased vulnerability and risk.

Declaration of interest None.
The recent Bradley report ${ }^{1}$ has renewed interest in the mental healthcare of offenders. In response, the government launched an ambitious delivery plan making a commitment to increase support for the growing number of people with mental illness in prison and elsewhere in the criminal justice system. ${ }^{2}$ Central to the plan are the notions of working in partnership, continuity of care, and equivalence - the premise that prisoners have the right to the same standard and quality of healthcare as the wider community.

Medication is a cornerstone of modern psychiatric care. ${ }^{3}$ Appropriate prescribing in prisons can have a positive impact on individual patients and the prison regime as a whole by helping to reduce symptom severity, violence and aggression and illicit drug taking so that individuals can participate in purposeful activity. ${ }^{4,5}$ Current UK prison mental health policy states that prescribed medication should not be automatically stopped on entry to prison without proper psychiatric assessment. ${ }^{6}$ Indeed, abrupt cessation of psychiatric medicines may precipitate discontinuation symptoms and even relapse. ${ }^{3,7}$ Nonetheless, a common complaint among prisoners is that medication for mental health problems is frequently either withheld temporarily or stopped completely when they are received into custody. ${ }^{8-10}$ This problem should not be dismissed lightly given the increased risk of self-harm and suicide during the early period of custody. ${ }^{11}$

This study aimed to identify all prisoners who reported being prescribed psychiatric medication at prison reception and estimate the proportion of prescriptions for psychiatric medications that were continued on entry to prison. It also sought to establish the factors associated with discontinuation of medication.

\section{Method}

\section{Sample}

We undertook a retrospective case-note review at five prisons (A-E) located in northern England, all of which accepted remand and convicted prisoners directly from court. Data were collected between June 2008 and March 2009. Sites participated on a voluntary and confidential basis and were selected to represent a range of prisoner populations (Table 1).

At each prison, a different calendar month was chosen during which prison records were sampled. Prison reception records were used to generate a list of all prisoners newly received into custody within that month. Prisoners transferred from other establishments were excluded. We gathered and reviewed clinical records, with assistance from prison healthcare staff. In total, 95\% $(n=1006)$ of the records eligible for inclusion were successfully reviewed (Table 1). Availability of records was lowest in prison E, the only prison at which an electronic records system had not yet been introduced. 


\begin{tabular}{|c|c|c|c|}
\hline Prison: type ${ }^{a}$ & $\begin{array}{c}\text { New receptions in month } \\
n\end{array}$ & $\begin{array}{c}\text { Records reviewed } \\
n(\%)^{b}\end{array}$ & $\begin{array}{c}\text { Mental health medication } \\
\text { pre-custody } \\
n(\%)^{c}\end{array}$ \\
\hline A: adult male local & 262 & $260(99)$ & $56(22)$ \\
\hline B: adult male local & 302 & $298(99)$ & $51(17)$ \\
\hline C: adult and young female local & 68 & $66(97)$ & $23(35)$ \\
\hline D: adult male local & 296 & $296(100)$ & $46(16)$ \\
\hline E: male young offenders institution & 130 & $86(66)$ & $9(10)$ \\
\hline All & 1058 & $1006(95)$ & $185(18)$ \\
\hline
\end{tabular}

a. Names omitted to preserve confidentiality.

b. Denominator is percentage of new receptions in month.

c. Denominator is number of records reviewed.

\section{Procedure}

Using reception health screening records, we identified all cases where a prisoner reported being on psychiatric medication before being placed in custody. This was defined as any prescribed antidepressant, antipsychotic, hypnotic, anxiolytic and/or central nervous system (CNS) stimulant medication, as listed in the British National Formulary (BNF) chapter 4.1-4.4. ${ }^{12}$ A total of 185 records (18\% of the total) met this criterion (Table 1 ).

In all 185 cases, the following details were extracted from the notes: name and dose of pre-custody medication (as reported by the prisoner); details of communication between prison healthcare staff and community prescribers to verify prescriptions; name and dose of medications prescribed in prison; evidence of psychiatric assessment in prison; and evidence of reasons documented for nonprescription, where applicable. Following discussions within the study team, a cut-off of 1 week from reception into prison was chosen for prescriptions to be continued or evidence of reasons for discontinuation to be ascertained. Thus, only entries made in records during the first week of custody were considered.

\section{Analysis}

Data were analysed using SPSS version 16 for Windows. Individual medications were categorised in line with the BNF. Descriptive statistics (frequencies and percentages) were used to describe reported prescribed medication use prior to and during custody. We calculated 95\% confidence intervals for key findings. Chi-squared tests were used to test for associations between categorical variables. Significance was set at the $P<0.05$ level.

\section{Results}

\section{Prescribed medication prior to custody}

Of newly received prisoners, $18 \%$ (95\% CI 16-21) reported being prescribed psychiatric medication prior to custody (Table 1). Women were more likely to report being in receipt of psychiatric medication than men $\left(\chi^{2}=12.7, P<0.001\right)$. Prisoners arriving at the male young offenders institution were less likely than those at other prisons to report being in receipt of psychiatric medication $\left(\chi^{2}=3.9, P=0.047\right)$.

In total, the 185 prisoners identified 240 separate psychiatric medications at prison reception (Table 2). Of these, antidepressants accounted for approximately half of all medications (52\%), followed by hypnotics/anxiolytics (34\%) and antipsychotics (14\%). No prisoners in the sample reported being in receipt of CNS stimulants. Most prisoners (58\%) reported being in receipt of only one psychiatric medication, $28 \%$ said they received two different medications and $15 \%$ reported three or more (Table 3). Women were more likely than men to report being prescribed two or more psychiatric medications $\left(70 \%\right.$ v. $40 \% ; \chi^{2}=16.4$, $P<0.001)$.

\begin{tabular}{|c|c|c|c|c|c|}
\hline \multirow[b]{2}{*}{ Prison } & \multicolumn{5}{|c|}{$n(\%)$} \\
\hline & Hypnotics/anxiolytics & Antipsychotics & Antidepressants & CNS stimulants & Any \\
\hline A & $26(43)$ & $2(3)$ & $32(53)$ & $0(0)$ & $60(100)$ \\
\hline B & $21(28)$ & $16(21)$ & $38(51)$ & $0(0)$ & $75(100)$ \\
\hline $\mathrm{C}$ & $16(50)$ & $2(6)$ & $14(44)$ & $0(0)$ & $32(100)$ \\
\hline $\mathrm{D}$ & $14(23)$ & $12(20)$ & $35(57)$ & $0(0)$ & $61(100)$ \\
\hline $\mathrm{E}$ & $5(42)$ & $2(17)$ & $5(42)$ & $0(0)$ & $12(100)$ \\
\hline All & $82(34)$ & $34(14)$ & $124(52)$ & $0(0)$ & $240(100)$ \\
\hline
\end{tabular}

BNF, British National Formulary; CNS, central nervous system. 
Table 3 Proportion of psychiatric medication continued within 7 days of reception into custody, by BNF chapter

\begin{tabular}{lcccc} 
& \multicolumn{4}{c}{$n(\%)$} \\
\cline { 2 - 5 } Prison & Hypnotics/anxiolytics & Antipsychotics & Antidepressants & Any \\
\hline A & $14(54)$ & $1(50)$ & $27(84)$ & $42(70)$ \\
\hline B & $10(48)$ & $10(63)$ & $24(63)$ & $44(59)$ \\
\hline D & $8(50)$ & $0(0)$ & $13(57)$ & $16(50)$ \\
\hline E & $3(21)$ & $1(50)$ & $2(40)$ & $22(36)$ \\
\hline All & $1(20)$ & $18(53)$ & $74(60)$ & $128(53)$ \\
\hline
\end{tabular}

BNF, British National Formulary.

\section{Prescriptions during custody}

For each of the individual psychiatric medications identified at prison reception, we determined whether the medication was continued within 1 week of reception into custody. It appeared that $53 \%$ (95\% CI 47-60) of all prescriptions were continued within 1 week of reception into custody, although prescribing rates varied between prisons (33-70\%) (Table 3). Hypnotics/anxiolytics were less likely to be continued than other medication types $\left(\chi^{2}=4.5, P=0.035\right)$. Women were no more likely than men to have their medication continued $\left(\chi^{2}=0.2, P=0.685\right)$.

Overall, $47 \%$ of prescriptions $(n=112)$ were not continued within 1 week of arrival in prison. In two cases (2\%) this was because prisoners refused their medication in prison. The following factors were positively and significantly associated with discontinuation of medication: response from a community prescriber stating there was no current valid prescription for the medication (21\%, $\left.n=23 ; \chi^{2}=18.1, \quad P<0.001\right)$; prescription of a substitute medication from the same category of the BNF (17\%, $n=19 ; \chi^{2}=23.6, P<0.001$ ); and discharge (release/transfer) within the first week of custody $\left(21 \%, n=23 ; \chi^{2}=9.4\right.$, $P=0.002$ ). Receiving a psychiatric assessment within the first week of custody was not associated with discontinuation of medication $\left(11 \%, n=12 ; \chi^{2}=0.2, P=0.667\right)$. In $43 \%$ of cases where psychiatric medication was discontinued $(n=48)$, the prisoner remained in custody for at least 1 week and there was no evidence of patient refusal, disconfirmation from a community prescriber, provision of substitute medication or psychiatric assessment.

\section{Discussion}

Almost a fifth of prisoners entering prison (18\%) reported that they were currently receiving prescribed psychiatric medication. However, prescriptions for $47 \%$ of the medications reported at prison reception were not continued during the first week of custody, in many cases (43\%) without a discernable reason.

\section{Strengths and limitations}

Confidence can be drawn from the large number of patient records sampled in this study, comprising 95\% of those eligible for inclusion. This was largely thanks to the assistance of local prison healthcare staff and availability of electronic record systems in all but one prison. Nonetheless, as only local prisons in the north of England were sampled, care must be taken when generalising our findings to other prison types or geographical regions. Furthermore, we were only able to capture entries made in clinical records during the first week of custody; unrecorded clinical activity or entries made outside this period would have been missed. Similarly, we did not seek to determine whether medication was actually dispensed or administered to the patient.

Our findings are consistent with those of previous studies, ${ }^{8-10}$ confirming that the supply of psychiatric medicines is often interrupted for newly received prisoners. Previously published research in this area has been largely small scale and qualitative. Although such studies have the advantage of generating rich data on participant experiences, in doing so they necessarily focus on prisoner selfreport. By using clinical records, our study was uniquely able to evidence and quantify the extent of continuity of prescribing between community and prison. In cases where prisoners were not prescribed the same medication in prison, we sought to discern the reasons behind this: for example, where clarification from outside services had revealed that a prisoner had not been prescribed that medication in the community or where a substitute medication had been prescribed in custody.

\section{Discontinuation of medication on prison entry}

Current UK best practice guidelines advise that stopping or reducing doses of psychiatric drugs should be done on a gradual basis and with careful monitoring. ${ }^{13,14}$ Furthermore, prison mental health policy clearly states that medication for mental disorder should not be automatically withdrawn on entry into prison without proper clinical assessment. ${ }^{6}$ Yet, the findings of this study indicate that in almost half of cases continuity of medicines' supply was disrupted on entry into custody, often without any discernable reason recorded in the notes.

In some cases in this study we can logically infer that medication was discontinued as a result of active decisionmaking; this would include cases where substitute drugs were given, medications were disconfirmed by community prescribers, and/or psychiatric assessments were completed. In other cases, mitigating circumstances were present such as prisoners being in custody for very short periods, leaving prison staff insufficient time to verify and 
arrange prescriptions. However, in almost half of cases where medication was discontinued $(43 \%)$, none of these conditions applied. It is not clear whether prescriptions were deliberately stopped for reasons not identified by this study or whether medication needs were simply overlooked. Notwithstanding, taken in the context of studies citing significant prisoner distress caused by changes to medication, ${ }^{8-10}$ this finding is concerning.

\section{Adverse effects of abrupt medication discontinuation}

We do not dispute that managed discontinuation of medication may, where appropriate, have the potential to benefit a patient. Indeed, patients themselves might request to reduce or stop their medication (two patient refusals were noted in this study). Abrupt withdrawal of psychiatric medication without proper clinical management, however, can have potentially serious health consequences. Discontinuation symptoms can include marked psychological and somatic symptoms (e.g. anxiety, insomnia, dizziness) and can start abruptly within a few days of stopping medication. ${ }^{15-17}$ Moreover, there may be a risk of relapse of the underlying condition. If medication is withdrawn against the wishes of the patient, it may also contribute to feelings of powerlessness and mistrust, and could discourage prisoners from taking responsibility for managing their illness. ${ }^{9}$ Denial of medication immediately following entry to prison also potentially adds to risk at an already distressing time; indeed, a third of all deaths by suicide in UK prisons occur within the first week in custody. ${ }^{11}$

We recognise that prison healthcare staff work in highpressure environments, with the added challenge of balancing security needs with prisoners' health needs. Newly received prisoners frequently arrive at reception en masse, often outside of normal general practice hours and without any physical evidence of existing treatment plans or prescriptions. Furthermore, because of the high incidence of illicit drug use in prisons, certain medications can become 'currency'. There is also a commonly held perception among staff that some prisoners may make false claims in order to extract valued medication from prescribers. ${ }^{9}$ This might explain why this study found that hypnotics/anxiolytics were the least likely medication type to be continued in custody. Complete discontinuation, however, may be a clinically risky strategy given that abrupt cessation of some medications of this type has been associated with severe discontinuation symptoms, including seizures. ${ }^{18}$

\section{Systemic issues}

In highlighting the specific case of the prescription of psychiatric medication, the findings of this study allude to issues arguably endemic in prison healthcare: risk, mistrust, role conflict and poor information-sharing systems. Such factors complicate the process of continuing prescriptions for those genuinely in receipt of psychiatric medication: in the words of an ex-prisoner, 'not all prisoners are addicts or skivers, yet we are treated as if we are. ${ }^{19}$ Nonetheless, we noted differences in prescribing rates between establishments, which suggests local variation in practices and procedures. If individual prisons have developed systems that better support continuity and equivalence of care for prisoners with mental illness, this may be a cause for some optimism, and fuller exploration of such local strategies is warranted to determine whether these ostensibly successful practices can be replicated elsewhere. Usefully, there appears to be a wealth of existing guidance (under the heading of medicines reconciliation) relevant to developing effective systems for recording medication information among patients being admitted to hospital, which could readily be applied to prison settings. ${ }^{20,21}$ Recommendations for standardising information-gathering procedures, establishing minimum data-sets of medication information and clarifying the roles and responsibilities of staff involved would appear to hold as much relevance for healthcare staff working in prisons as in hospitals.

In summary, imprisonment represents an opportunity for reviewing, continuing or improving therapeutic interventions in an otherwise transient and difficult-to-engage patient population. However, all too often it is experienced by prisoners as a disruption in care. This study has shown that continuity of psychiatric medicines' supply is not assured on entry into prison. This is concerning in light of known high rates of self-harm and suicide in early custody. Given that most prisoners serve short sentences and that all but a few are returned to the community eventually, interest in the findings of this study should not just be limited to prison-based practitioners. Although responsibility for providing patient care might initially be assumed by prisons, this will usually be short lived, immediately ceasing on release. Community and prison-based prescribers must therefore recognise their shared duty for ensuring continuity of care if medicines' supply for offenders with mental illness is to be maintained across setting boundaries.

\section{Acknowledgement}

We express our sincere thanks to the prisons that participated in this study and gratefully acknowledge the healthcare staff that facilitated work at individual sites.

\section{About the authors}

Lamiece Hassan is Research Assistant, Offender Health Research Network University of Manchester, and Lancashire Care NHS Foundation Trust, Preston, Jane Senior is Research Manager, Offender Health Research Network, University of Manchester, Dawn Edge is Research Fellow, School of Community Based Medicine, University of Manchester, and Jenny Shaw is Professor of Forensic Psychiatry, Offender Health Research Network, University of Manchester, and Lancashire Care NHS Foundation Trust, Preston

\section{References}

1 Bradley K. The Bradley Report: Lord Bradley's Review of People with Mental Health Problems or Learning Disabilities in the Criminal Justice System. Department of Health, 2009.

2 Department of Health. Improving Health, Supporting Justice: The National Delivery Plan of the Health and Criminal Justice Programme Board. Department of Health, 2009.

3 Bullmore $\mathrm{E}$, Fletcher $\mathrm{P}$, Jones $\mathrm{PB}$. Why psychiatry can't afford to be neurophobic. Br J Psychiatry 2009; 194: 293-5. 
4 Dolan KA, Shearer J, MacDonald M, Mattick RP, Hall W, Wodak AD. A randomised controlled trial of methadone maintenance treatment versus wait list control in an Australian prison system. Drug Alcohol Depend 2003; 72: 59-65

5 Department of Health. A Pharmacy Service for Prisoners. Department of Health, 2003.

6 Department of Health, HMPS. Changing the Outlook: A Strategy for Developing and Modernising Mental Health Services in Prison. Department of Health, 2001.

7 Haddad PM, Anderson IM. Recognising and managing antidepressant discontinuation symptoms. Adv Psychiatr Treat 2007; 13: 447-57.

8 Plugge E, Douglas N, Fitzpatrick R. Patients, prisoners or people. Women prisoners' experience of primary care in prison: a qualitative study. $\mathrm{Br} J$ Gen Pract 2008; 58: e1-8.

9 Bowen RA, Rogers A, Shaw J. Medication management and practices in prison for people with mental health problems: a qualitative study. Int $J$ Ment Health Syst 2009; 3: 24

10 Condon L, Hek G, Harris F, Powell J, Kemple T, Price S. Users' views of prison health services: a qualitative study. J Adv Nurs 2007; 58: 216-26.

11 Shaw J, Baker D, Hunt IM, Moloney A, Appleby L. Suicide by prisoners. National clinical survey. Br J Psychiatry 2004; 184: 263-7.

12 BMJ Group, Royal Pharmaceutical Society of Great Britain. British National Formulary 58. BMJ Group \& Pharmaceutical Press, 2009.
13 National Institute for Health and Clinical Excellence. Depression: The Treatment and Management of Depression in Adults (Update). NICE, 2009

14 National Institute for Health and Clinical Excellence. Schizophrenia: Core Interventions in the Treatment and Management of Schizophrenia in Adults in Primary and Secondary Care. NICE, 2009.

15 Moncrieff J. Does antipsychotic withdrawal provoke psychosis? Review of the literature on rapid onset psychosis (supersensitivity psychosis) and withdrawal-related relapse. Acta Psychiatr Scand 2006; 114: 3-13.

16 Lejoyeux M, Ades J. Antidepressant discontinuation: a review of the literature. J Clin Psychiatry 1997; 58 (suppl 7): 11-6.

17 Moncrieff J. Why is it so difficult to stop psychiatric drug treatment? It may be nothing to do with the original problem. Med Hypotheses 2006; 67: 517-23.

18 Fialip J, Aumaitre O, Eschalier A, Maradeix B, Dordain G, Lavarenne J. Benzodiazepine withdrawal seizures: analysis of 48 case reports. Clin Neuropharmacol 1987; 10: 538-44.

19 Mellor PA. The inside story on prison health care. BMJ 2003; 326: 59.

20 National Prescribing Centre. Medicines Reconciliation: A Guide to Implementation. National Prescribing Centre, 2008.

21 National Institute for Health and Clinical Excellence. PSG001 Technical Patient Safety Solutions for Medicines Reconciliation on Admission of Adults to Hospital. NICE, 2007.

\title{
Evaluating treatment of Axis I mental health disorders in Aceh, Indonesia
}

\author{
Neil Boothby, ${ }^{1}$ Maggie Veatch, ${ }^{1}$ Matina Pentes ${ }^{2}$
}

The Psychiatrist (2011), 35, 248-255, doi: 10.1192/pb.bp.110.030205

${ }^{1}$ Program on Forced Migration and Health, Mailman School of Public Health, Columbia University, New York; ${ }^{2}$ John Snow International Inc, Boston

Correspondence to Neil Boothby (nb2101@columbia.edu)

First received 2 Mar 2010, final revision 30 Nov 2010, accepted 28 Jan 2011

\begin{abstract}
Aims and method To share evaluation findings of a new decentralised mental healthcare system addressing Axis I disorders, developed in four subdistricts of Aceh Besar in Indonesia following the 2004 Asian tsunami. Two complementary methodologies were employed: an adequacy survey that assessed whether agreed programme implementation tasks were completed, and an outcome study that utilised patient, caregiver and staff assessment of the programme to determine what changes, if any, resulted from participation in the programme.

Results The system is functional in 3 of 4 subdistricts, and 47 of 53 subdistrict clinics (puskesmas) have trained mental healthcare nurses. Both patients and caregivers reported statistically significant differences when ranking patient wellbeing and were able to qualitatively describe specific changes in patient symptomatology and social functioning.
\end{abstract}

Clinical implications Results indicate that (a) the creation of a decentralised system with outreach at multiple levels, (b) emphasis on staff capacity building within a wider household-to-hospital continuum of care, and (c) incorporation of community volunteers working with trained medical personnel led to effective treatment options for people with Axis I disorders in a resource-poor setting.

Declaration of interest M.P. is employed by John Snow Inc.
A significant portion of the global burden of disease has been attributed to mental illness, which accounted for $13 \%$ of all the disability-adjusted life-years lost in 2003. Additionally, approximately $33 \%$ of all years lived with disability are attributed to neuropsychiatric conditions. ${ }^{1-5}$ This burden of mental illness is expected to rise, and yet despite increasing documentation of its tremendous negative impact worldwide, treatment has largely been 